\title{
Low-magnification electron micrography of leproma in human skin based on semithin and ultrathin sectioning
}

\author{
T HIRATA
}

Research Training Section and Electron Microscopic Laboratory, 2-1, 4-Chome, Aobacho, Higashimurayamashi, Tokyo 189, Japan

\begin{abstract}
Accepted for publication 12 March 1990
Summary Low-magnification electron micrography of leprosy lesions is described. The various cell types in the lesions, the relationships to leprosy bacilli and the distribution of bacilli in the lesions of lepromatous leprosy, are neatly demonstrated in the low-magnified pictures.
\end{abstract}

\section{Introduction}

It is well known that electron microscopy (EM) combined with ultrathin sectioning has helped enormously in understanding the interrelationships between leprosy bacilli and various kinds of host tissue cells in leprosy lesions. The late Dr Nishiura' said very appropriately: 'We are now faced with the problems of reestablishing the pathology of leprosy based on the new morphology of lesions, with this technologic advancement of morphologic research.' Since then many papers on EM in leprosy have been published. However, there is no paper to show the microcytopathological analysis of leprosy lesions by low-magnification electron micrography of $\times 500-1000$. The present paper is concerned with a rigorous study of how to take such low-magnified micrographs of human skin leproma. Considerable success has been achieved in obtaining satisfactory results.

\section{Materials and methods}

HUMAN LEPROMAS

Tissue specimens from lepromatous leprosy patients with fresh lepromas were examined by skin biopsy. The biopsies were collected at the National Leprosarium of Oku Kohmyoen, Okayama and Tama Zensho-en, Tokyo.

PREPARATIONS OF TISSUES FOR ELECTRON MICROSCOPY

Prefixation

The biopsies were prefixed by imimersion in $2-8 \%$ glutaraldehyde aqueous solution for one week at room temperature. 


\section{Washing and rinsing}

The prefixed materials were washed in running water for a few hours, then rinsed in distilled and/or double distilled water a few times.

\section{Immersing in agar solution}

The washed and rinsed materials were cut into $0.5-1.0 \mathrm{~mm}$ cubes. The cubes were placed in $2 \%$ agar sol at $45^{\circ} \mathrm{C}$. After cooling and gelation, the agar was cut into small blocks. (This method greatly facilitated transfer of specimens from one solution to another.)

\section{Fixation}

The small blocks were fixed by immersion in osmium tetroxide buffered to $\mathrm{pH} 6 \cdot 8-7 \cdot 0$ according to the technique of Millonig. ${ }^{2}$ Fixation time was 48 hours at $4{ }^{\circ} \mathrm{C}$.

\section{Dehydration}

The specimens were dehydrated by serial passage (15-30 min. each) into 50, 70, 80, 90, 95 and $100 \%$ ethanol. Following this, the specimens were washed $2-3$ additional times with fresh absolute ethanol.

\section{Treatment with methacrylate resins}

Methacrylate resins, methyl methacrylate and $n$-butyl methacrylate, as supplied by the manufacturer, contain a hydroquinone inhibitor. The inhibitor was removed by preliminary treatment with $2 \%$ sodium hydroxide solution at room temperature. After two or three treatments, the solution should be colourless. The resins were washed several times with distilled and/or double distilled water to remove the alkali, dehydrated by anhydrous calcium chloride, and stored in a refrigerator. Any particles of the agent must be removed by filtration before the resins are used for embedding.

The dehydrated specimens were transferred to a $50 \%$ solution of the methacrylate resins in absolute alcohol and left $1-2$ hours. The use of resins containing $1 \cdot 5 \%$ benzoylperoxide as catalyst was tested in place of the usual 3 to 7 mixtures of methyl and $n$-butyl methacrylate. The specimens were then passed two or three times ( 1 hour each) through undiluted resins.

\section{Polymerization}

Polymerization was carried out by placing the specimens in gelatin capsules and filling them with the unpolymerized resins. The temperatures employed were room temperature (4-5 h $*), 35-37^{\circ} \mathrm{C}(1-2$ days $), 45^{\circ} \mathrm{C}(1-2$ days $)$ and $60^{\circ} \mathrm{C}$ ( $2-4$ days). After $1-1 \cdot 5$ days at $35-$ $37^{\circ} \mathrm{C}$, the capsules filled with the partially polymerized resins were slowly swayed for $1-2$ min. Upon completion of polymerization, the capsules were kept in the vacuum desiccator (EM-DSC 10E, JEOL). 


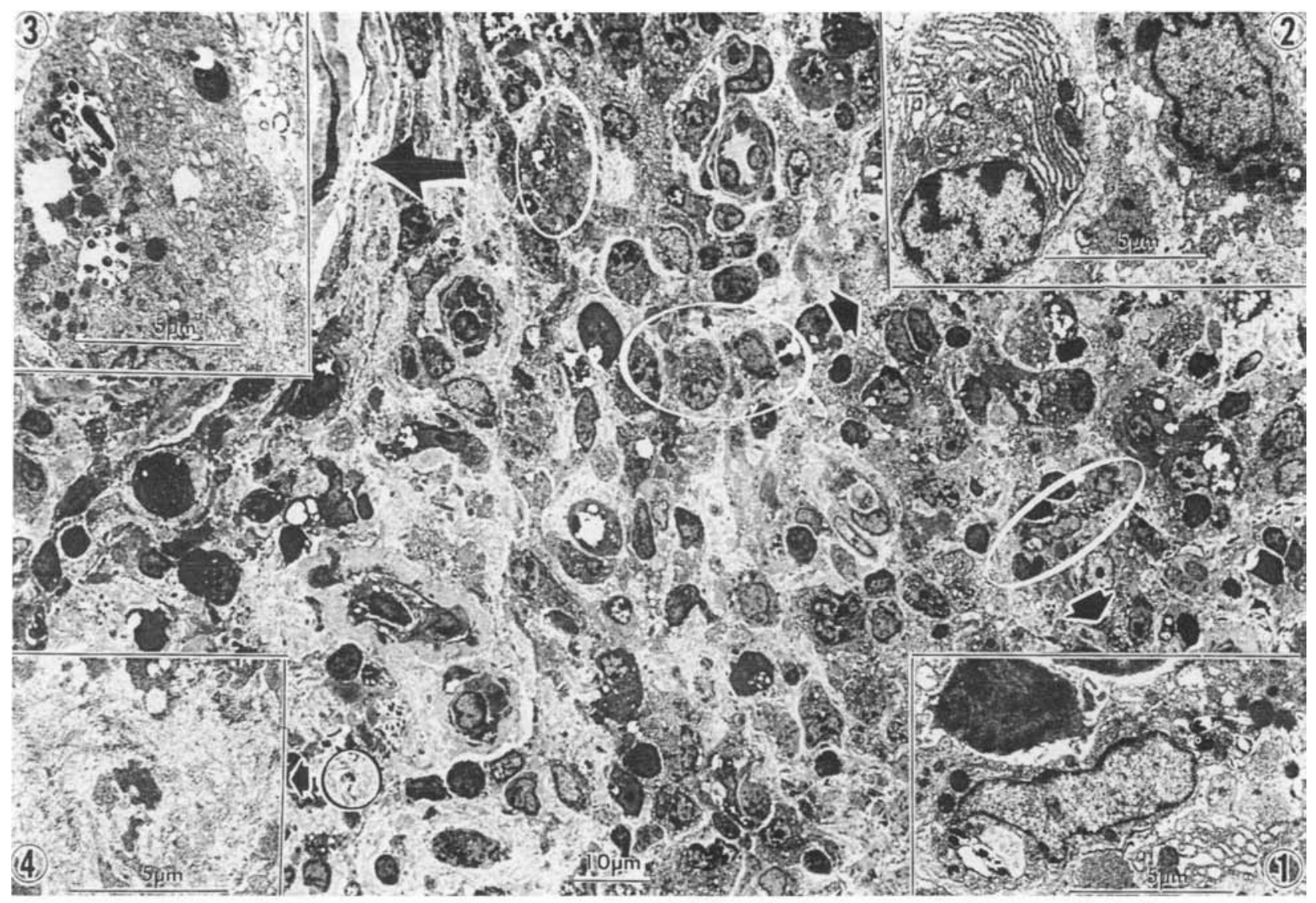

Figure 1. Low-magnified electron micrograph (original $\times 500$ ). Several parts (insets 1-4) are trimmed, greatly magnified, along with the original. Photo 1 is the nucleus in macrophage and the bacilli in the cell; Photo 2, the plasma cell and the macrophage; Photo 3, the macrophage and the bacilli in the cell; Photo 4 , the collagen fibres. 


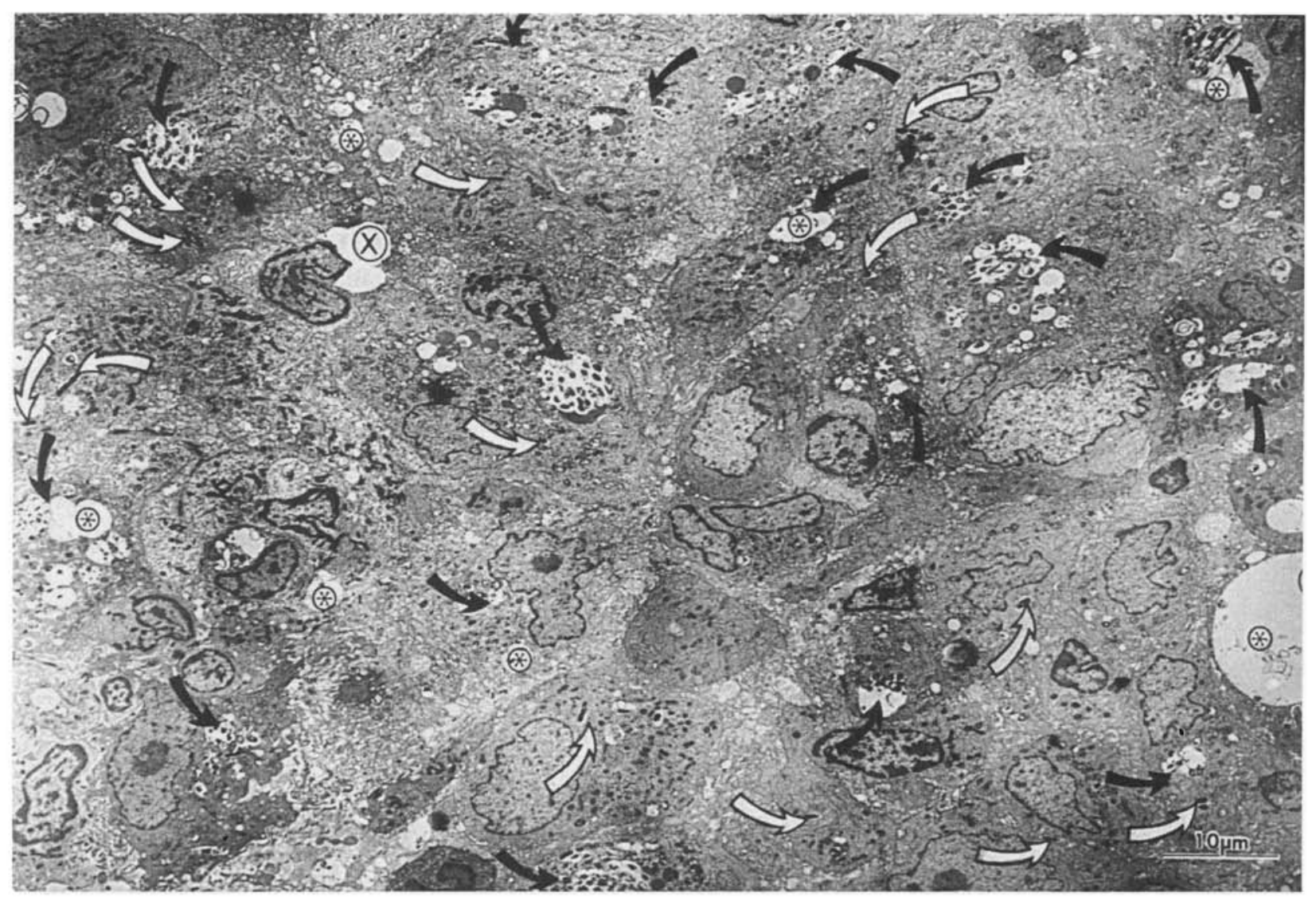

Figure 2. Low-magnified electron micrograph (original $\times 500$ ). The various cell types in the lesions, the relationships to leprosy bacilli and the

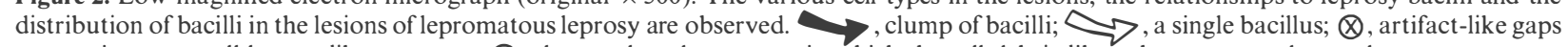
or openings as small lacuna-like structure; $\circledast$, electron less dense parts in which the cell debris-like substances are detected. 


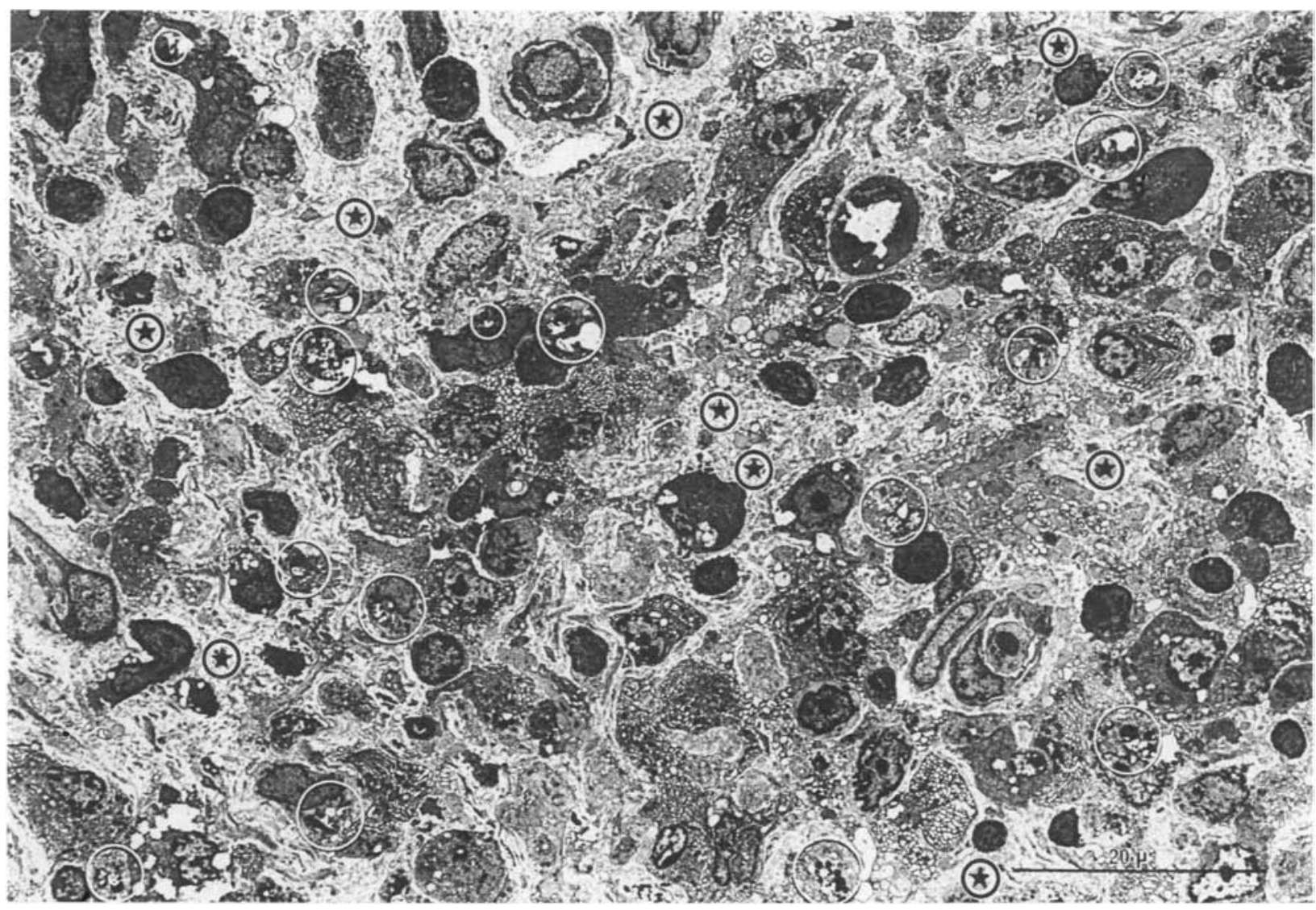

Figure 3. Low-magnified electron micrograph (original $\times 500$ ). Fine fibrillar structures $(\boxplus)$ are observed. It may be assumed that they are collagen fibres. In the circle-marks are shown the bacilli and the relative tissue cells. 


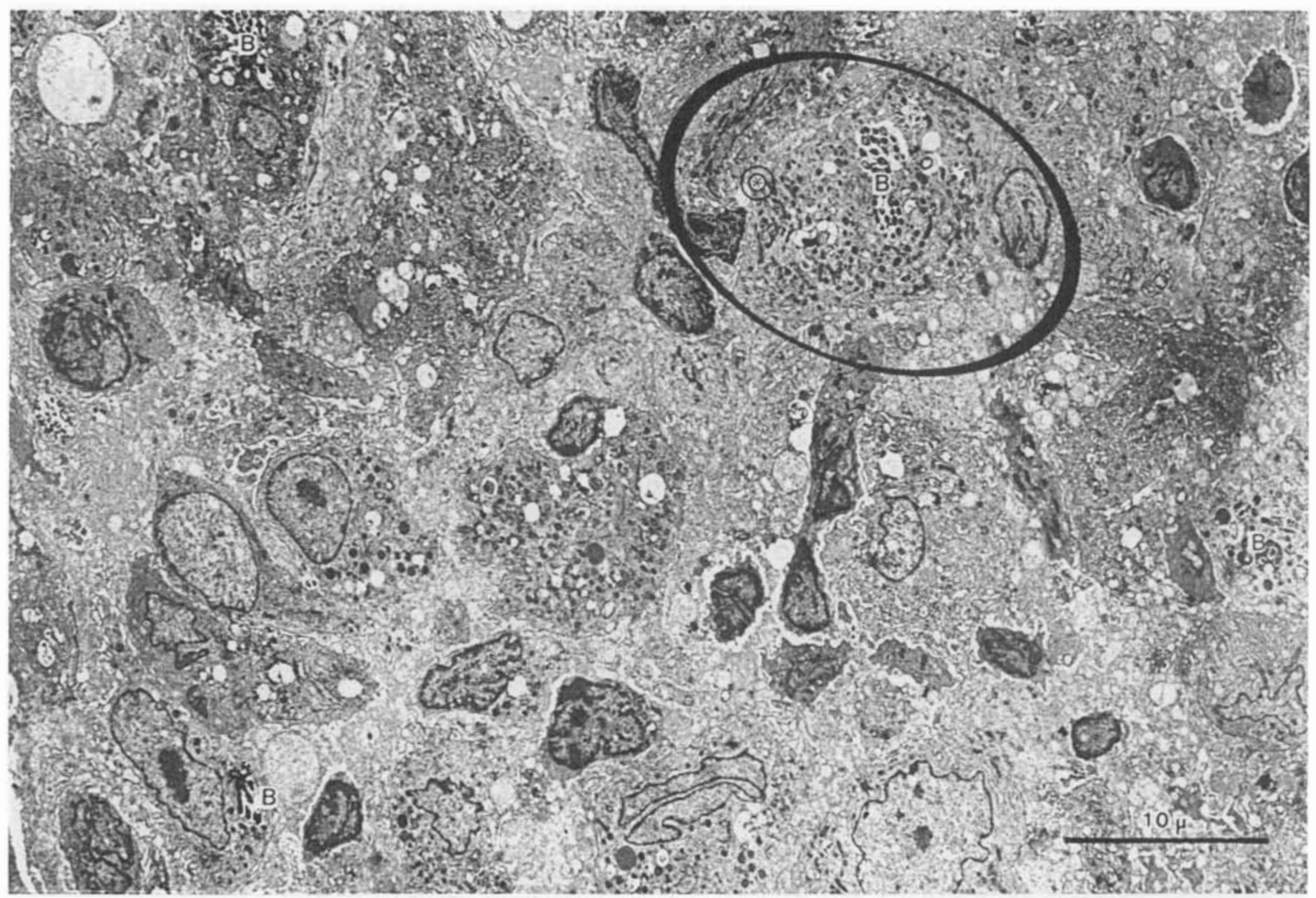

Figure 4. Low-magnified electron micrograph (original $\times 900$ ). The so-called macrophages are pictured sporadically. $B=$ leprosy bacilli. 


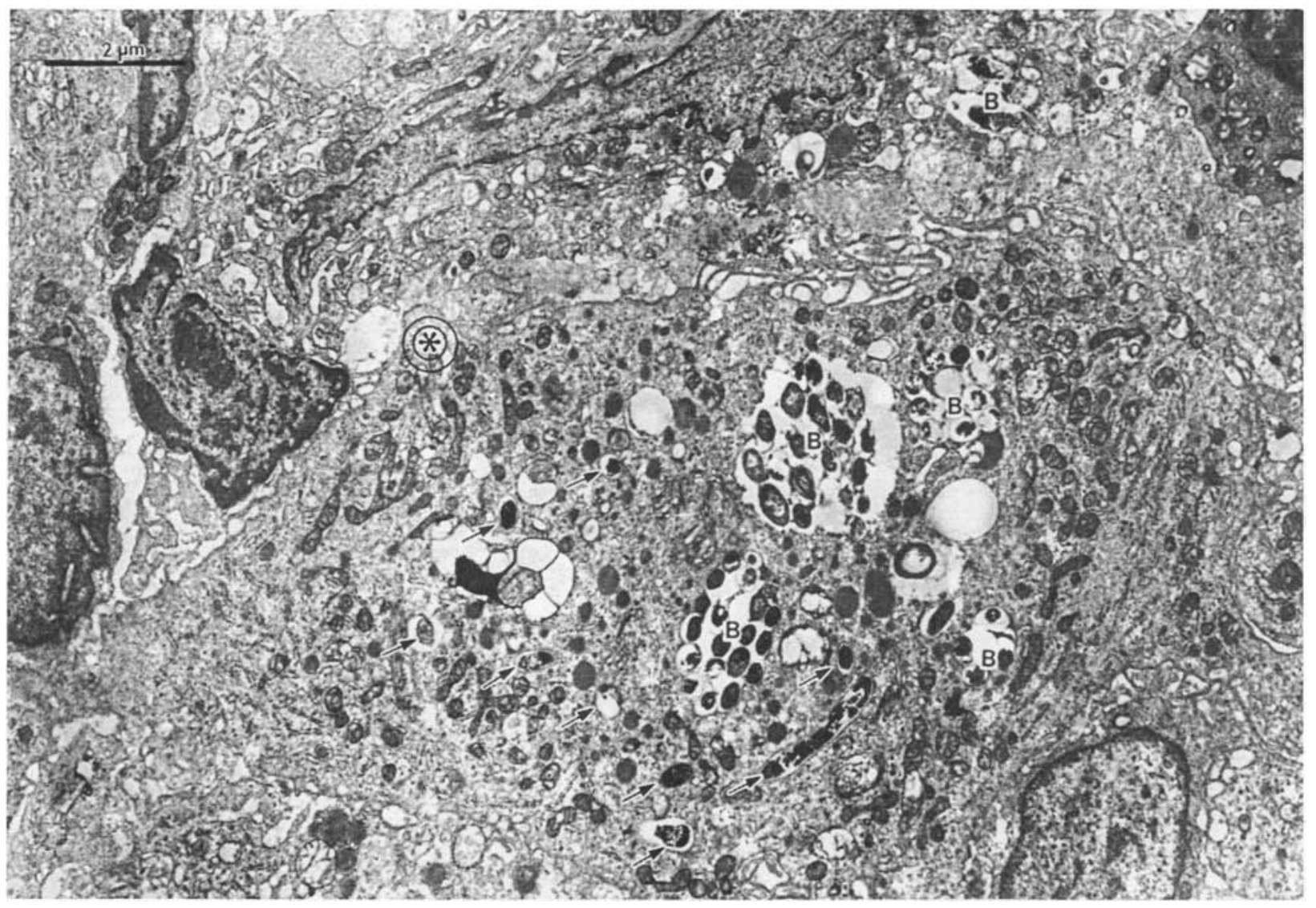

Figure 5. High-magnified electron micrograph of the circle $(\circledast)$ ) in Figure 4 (original $\times 3000$ ). The whole aspect of one macrophage is depicted. Arrows show the single bacillus. $\mathrm{B}=$ leprosy bacilli in the clump or group called globi. 

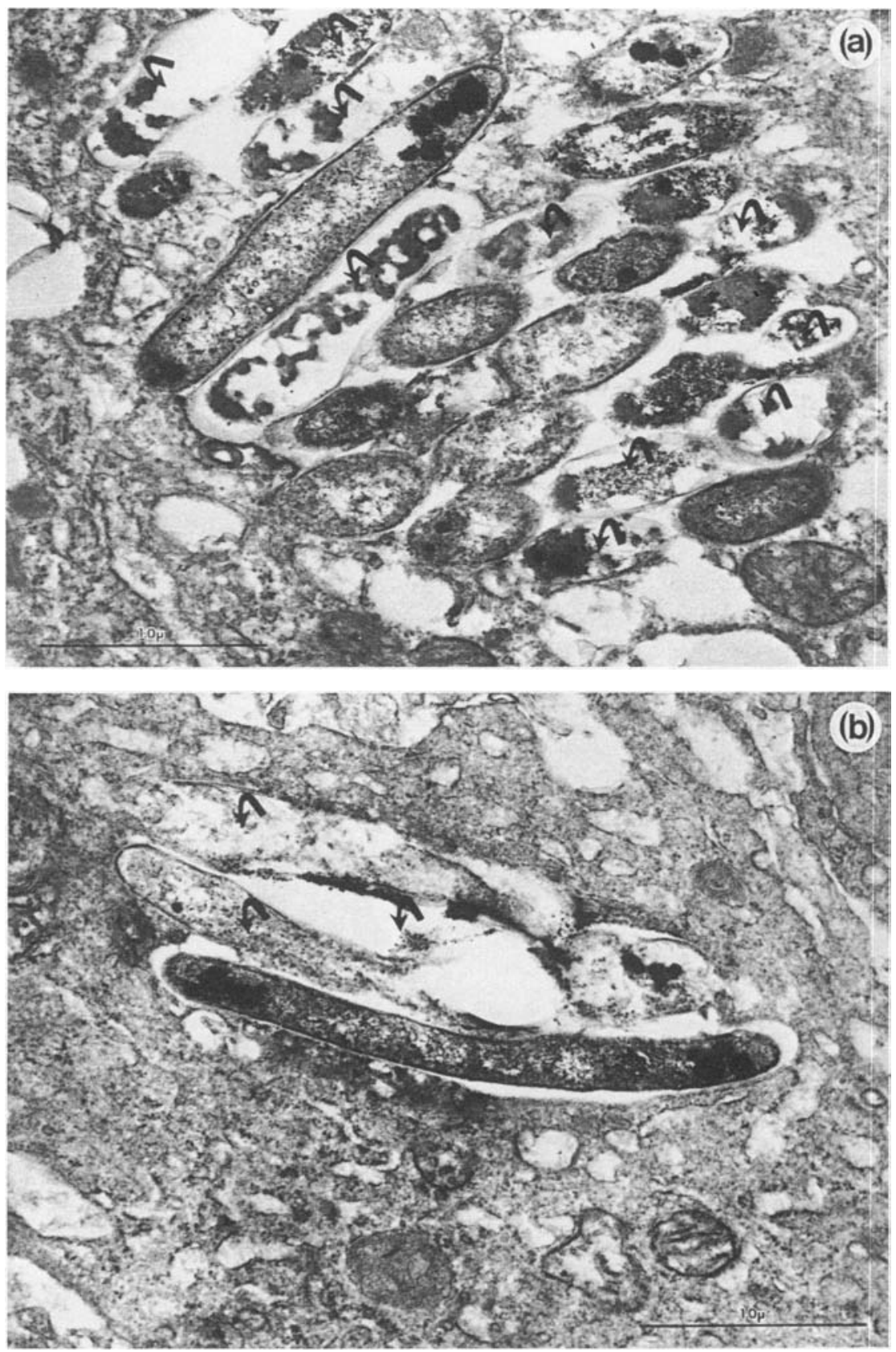

Figure 6. Thin sections of a group of bacilli. $1=$ degenerated bacilli: (a) Longitudinal and oblique sections of the bacilli. There are several intracytoplasmic inclusions in the bacilli (original $\times 10,000$ ); (b) Longitudinal sections of the bacilli, intact and degenerated and arranged in parallel. Several intracytoplasmic inclusions are observed in an intact bacillus (original $\times 10,000$ ). 


\section{Sectioning and electron microscopy}

The semithin and ultrathin sections were processed on an LKB Ultratome and picked up on Formvar-covered grids. The sections were smoothed over by chloroform vapour. More than 500 sections of the specimens were made, and they were observed on a JEM $1200 \mathrm{EX}$ electron microscope operated at $40 \mathrm{kV}$, without electron staining as a general rule. If necessary, the sections were contrasted with the lead electron staining solution (Katayama Chemical Industries, Co. Ltd, Osaka, Japan). They were rinsed rapidly in distilled water, after contrasting. Pictures of the whole specimens were made at low magnifications; 500, 800, 1000, 1200, 1500 and 3000 diameters. The important and significant parts were filmed at high power magnification of $\times 5000$ to $\times 10,000$.

\section{Results}

The electron micrographs demonstrated in Figures 1-6 show that the processing of specimens for electron microscopic examination used here produced good results. The socalled polymerization damage, which results from conventional procedures of methacrylate embedding, seemed to be avoided.

The microcellular structures are in a fine state of preservation, both in host tissue and bacterial cells in the leproma. Consequently, it was possible to enlarge directly parts of the original negative film at high magnification (Figure 1). On scrutinizing the electron micrographs narrowly, however, two forms of artefact-like gaps were observed (Figure 2): electron less dense parts in which cell debris-like matter was detected, and small lacuna-like structures in which the cellular components were deemed non-existent. They did not seem to be the so-called lumen or lumen-like structures of the tissue.

Besides several kinds of tissue cells, the cell components of well-developed lepra cells were seen, as described in former papers: ${ }^{1,5,6}$ foamy structures, opaque droplets, electrotransparent zones, onion-like structures and other organelles. Macrographs with such cytoplasm were predominant in the specimens. And also fine fibrillar structures were observed as shown in Figure 3.

Bacilli in the leproma were distributed a globi and single bacillary cells (Figures 2-5). As shown in Figure 6(a) and (b), it was possible to elucidate the fine structures of such bacilli at higher magnification. The various intracellular structures of the intact bacillary cell were well preserved.

\section{Discussion}

Because of the polymerization damage which results from conventional procedures, methacrylate embedding has fallen into disuse lately, though impregnation is good and the specimens cut readily. The damage is said to be an explosion phenomenon that becomes evident during polymerization, not during fixation or dehydration. It is characterized by a degree of shrinkage and/or disruption of the tissue cells in biomaterials, with concomitant internal distortion. Under these conditions, electron microscopists have been forced, more or less unwillingly, to search for more suitable methods. ${ }^{5-11}$ Yet these kinds of damage were not detected in the present study, and the procedures used seemed good from this point of view, though the methods are not new. It may be safely said that good results depend upon the following points: (a) prolonged pre-fixing in 
glutaraldehyde aqueous solution; (b) preliminary immersing and embedding of the materials in agar; (c) fixing of the small agar blocks in osmium tetroxide; (d) removing and/or discarding hydroquinone inhibitor from methacrylate resin; and (e) swaying the capsules filled with partially polymerized resins. (Some of these points have been reported previously. ${ }^{7}$ ) Moreover, a matter of great import is to carry out the preparatory procedures without haste.

The cells of the lesions show a characteristic morphologic pattern in their response to the parasites. To study their relationships, it is imperative to examine a wide area at low magnifications of $\times 500-1000$, and after that to examine selected areas at high magnifications of $\times 5000-10,000$. Only then are the intimate interrelationships between host and parasite clearly seen.

The electron microscopic features of various aspects of leprosy lesions have been described. 1,3,4,7 However, low-magnification electron micrography has been rarely employed though it is fundamental to a true comprehension of the lesions. It is primarily a research tool, but it provides a general view of the lesion that is helpful for patient evaluation, and provides data that otherwise is available only through histopathology. It acts as a bridge between light and electron microscopy. The results shown in this paper justify further studies of microcytopathology in leprosy.

\section{Acknowledgments}

I wish to express my thanks to all the staffs at the National Leprosarium of Oku Kohmyoen, Okayama and Tama Zensho-en, Tokyo, who helped in this study.

\section{References}

1 Nishiura M. The electron microscopic basis of the pathology of leprosy. Int J Lepr, 1960; 28: 357-400.

2 Millonig G. Further observations on a phos phate buffer for osmium solutions. The 5th International Congress for Electron Microscopy, Philadelphia, 1962 (S.S. Bress, Jr., editor). New York: Academic Press, Inc., 1962, 2,8 .

3 Imaeda T. Electron microscopic analysis of the components of lepra cells. Int J Lepr, 1960; 28: 22-37.

${ }^{4}$ Imaeda T, Convit J. Electron microscope study of Mycobacterium leprae and its environment in a vesicular leprous lesion. J Bacteriol, 1962; 83: 43-52.

5 Condie RM, Howell AE, Good RA. Studies on the problem of preservation of myelin sheath ultrastructure: evaluation of fixation, dehydration, and embedding. J Biophysic Biochem Cytol, 1961; 9: 429-43.

${ }^{6}$ Hashimoto T, Naylor HB. Studies of the fine structure of microorganisms. 1. A study of factors influencing the "Explosion Phenomenon" in ultrathin sections of bacteria. J Bacteriol, 1958; 75: 640-6.

7 Hirata T. Electron microscopic observations of cell wall and cytoplasmic membrane in murine and human leprosy bacilli. Int J Lepr, 1985; 53: 433-40.

${ }^{8}$ Holt SJ, Hicks RM. Studies of formalin fixation for electron microscopy and cytochemical staining purposes. J Biophysic Biochem Cytol, 1961; 11: 31-45.

9 Koike M, Takeya K. Fine structures of intracytoplasmic organelles of mycobacteria. J Biophysic Biochem Cytol, 1961; 9: 597-608.

10 Low FN, Clevenger MR. Polyester-methacrylate embedments for electron microscopy. J Cell Biol, 1962; 12: 615-21.

11 Pease DC. Histological techniques for electron microscopy. Academic Press: New York and London, 1960.

12 Ryter A, Kellenberger E. L'inclusion au polyester pour l'ultramicrotomie. J Ultrastruct Research, $1958 ; 2$ : 200-14.

13 Ward RT. Prevention of polymerization damage in methyacrylate embedding media. J Histochem Cytochem, 1958; 6: 398.

14 Watson ML. Reduction of heating artifacts in thin sections examined in the electron microscope. $J$ Biophysic Biochem Cytol, 1957; 3: 1017-31. 